\title{
Palmitate Induces TRB3 Expression and Promotes Apoptosis in Human Liver Cells
}

\author{
Weihui Yann ${ }^{a, c, d, e}$ Ying Wang ${ }^{a, c, d, e}$ Yongtao Xiao ${ }^{b, c, d}$ Jie Wen ${ }^{a, c, d} \quad J i a n g W^{a, c, d}$ \\ Lei Du ${ }^{b, c, d} \quad$ Wei Cai ${ }^{a, b, c, d}$
}

aDepartment of Clinical Nutrition, Xin Hua Hospital, Shanghai Jiao Tong University School of Medicine, ${ }^{b}$ Department of Pediatric Surgery, Xin Hua Hospital, Shanghai Jiao Tong University School of Medicine, 'Shanghai Institute of Pediatric Research, dShanghai Key Laboratory of Pediatric Gastroenterology and Nutrition, Shanghai China; eThese authors contributed equally to this work and share first authorship

\section{Key Words}

Tribbles homolog 3 - Palmitate - Endoplasmic reticulum stress - Cell viability - Akt phosphorylation

\begin{abstract}
Background/Aims: Parenteral nutrition-associated liver disease (PNALD) is a major complication for patients who require long-term parenteral nutrition. Treatment options for PNALD are limited and its pathogenesis is poorly understood. Tribbles homolog 3 (TRB3) is a pseudokinase that modulates many signal transduction cascades and may be involved in the pathogenesis of PNALD. The aim of this study was to examine the role of TRB3 in palmitateinduced endoplasmic reticulum (ER) stress, in the human liver cell line L02. Methods: L02 cells were treated with palmitate, and its effect on cell viability, mitochondrial membrane potential, apoptosis and TRB3 expression were assessed. The role of TRB3 was also studied using transient overexpression of TRB3 in L02 cells, as well as its interaction with Akt signaling. Results: We found that palmitate induced ER stress and apoptosis in L02 cells. Palmitateassociated ER stress was accompanied by a significant induction of TRB3 expression at the mRNA and protein level. Overexpression of TRB3 potentiated the deleterious effects of palmitate, which was associated with decreased levels of phospho-Akt. Conclusions: TRB3 is an important mediator of palmitate-induced apoptosis in human liver cells, suggesting that it may also be involved in the molecular mechanism underlying PNALD.
\end{abstract}




\section{Introduction}

Parenteral nutrition-associated liver disease (PNALD) is a major complication in patients requiring long-term parenteral nutrition [1]. There are few effective treatments for PNALD, and it is associated with a poor prognosis when the disease progresses to liver cirrhosis [2]. Indeed, PNALD is one of the most significant risk factors associated with mortality in infants on long-term parenteral nutrition [1]. The pathogenesis of PNALD is multifactorial and poorly understood, but several risk factors have been recognized [1-4]. For example, intravenous lipid emulsions, particularly phytosterols, have been implicated in the development of PNALD [1-3, 5]. It is generally accepted that accumulation of lipids in the liver can lead to lipotoxicity and apoptosis, which were demonstrated to be involved in PNALD [6-10]. Nevertheless, the exact molecular mechanism of apoptosis induced by lipid accumulation is unknown.

Stress within the endoplasmic reticulum (ER) induces the unfolded protein response (UPR), which helps the ER cope with the aggregation of misfolded proteins [11]. Unchecked ER stress and an ineffective UPR can result in the affected cells becoming apoptotic. ER stress and activation of the UPR have been linked to many human disorders, including obesity, type 2 diabetes, cancer, atherosclerosis and late-onset neurological diseases [11-13]. ER stress has also been reported in mammalian cells in response to various lipotoxic conditions [11, 14]. Indeed, recent evidence suggests that intracellular accumulation of saturated fatty acids induces ER stress and leads to lipotoxicity in the liver [11, 13-15]. Palmitic acid (C16:0) is one of the saturated fatty acids and its concentration in commonly used lipid emulsions Intralipide is $11.0 \mathrm{~mol} \%$ [16]. With this in mind, we hypothesize that ER stress may also be induced by lipid emulsions and associated with PNALD.

Tribbles homolog 3 (TRB3, also known as NIPK, SKIP3, TRIB3 and SINK) is a pseudokinase that modulates many signaling cascades associated with ER stress, nutrient deficiency, insulin resistance, hypoxia and the regulation of cell growth and differentiation [17-21]. Ohoka and colleagues reported that TRB3 is expressed in the human hepatoma cell line HepG2, and its expression level was increased during tunicamycin-induced ER stress [22]. Furthermore, the saturated fatty acid, palmitic acid, has been shown to induce TRB3 expression in podocytes [23]. It was shown that TRB3 can be induced in the liver by various stressors in vivo [24-26]. We have previously reported that oxidative injury and hepatocyte apoptosis might play an important role in the pathogenesis of PNALD $[9,10]$. Given the association between TRB3 and ER stress, we hypothesize that TRB3 is an important regulator of palmitate-induced apoptosis in human liver cells and might be involved in pathogenesis of PNALD. Therefore, we attempted to elucidate the regulation effect of TRB3 in the normal human liver cell line L02, which were treated with palmitate to induce ER stress. Our data is the first to show that palmitate induces TRB3 expression in L02 cells, and that this protein is an important mediator of palmitate-induced ER stress and apoptosis. We also demonstrated that overexpression of TRB3 suppresses the phosphorylation of the Akt pathway, leading to cell death in L02 cells.

\section{Materials and Methods}

\section{Cell lines and cell culture conditions}

The human normal hepatic cell line L02 was purchased from the Cell Bank of Type Culture Collection of the Chinese Academy of Sciences (Shanghai, China). Cells were cultured in Dulbecco's modified Eagle's medium (Gibco, Invitrogen, NY, USA) supplemented with 10\% fetal bovine serum (Gibco) and placed in a humidified, $5 \% \mathrm{CO}_{2}$ incubator (Thermo fisher scientific, Waltham, MA, USA) at $37^{\circ} \mathrm{C}$. 
was prepared in $100 \mathrm{mM} \mathrm{NaOH}$ at $70^{\circ} \mathrm{C}$ in a water bath for $3 \mathrm{~h}$. Meanwhile, a $10 \%$ solution of low free fatty acid BSA (MP Biomedicals, Santa Ana, CA, USA) was dissolved in $\mathrm{ddH}_{2} \mathrm{O}$ through gentle agitation at room temperature, and then heated at $55^{\circ} \mathrm{C}$ in a water bath for $15 \mathrm{~min}$. From these stock solutions, a 5 $\mathrm{mM}$ palmitic acid working solution was prepared by adding $50 \mu \mathrm{l}$ of $100 \mathrm{mM}$ sodium palmitate solution to $950 \mu \mathrm{l}$ of the $10 \% \mathrm{BSA}$ solution at $55^{\circ} \mathrm{C}$, which was then vortex mixed for $10 \mathrm{~s}$, followed by incubation at $55^{\circ} \mathrm{C}$ for $15 \mathrm{~min}$. The solution was then cooled to room temperature and the $\mathrm{pH}$ was adjusted to 7.4, followed by filter sterilization ( $0.45 \mu \mathrm{m}$ pore size membrane filter, Millipore, Darmstadt, Germany). The sterile solution was then aliquoted and stored at $-20^{\circ} \mathrm{C}$ until further use. Immediately prior to use, the stored $5 \mathrm{mM}$ palmitate $/ 10 \% \mathrm{BSA}$ stock solution was thawed and heated for $15 \mathrm{~min}$ at $55^{\circ} \mathrm{C}$, and then cooled to room temperature. Tunicamycin (Sigma) was dissolved in dimethyl sulfoxide (Sigma) at a concentration of $10 \mathrm{mg} / \mathrm{ml}$ for storage, and $10 \mu \mathrm{g} / \mathrm{ml}$ in DMEM for experimental use.

\section{Cell viability assay}

To determine the effects of sodium palmitate on L02 cells, cell viability was measured with a Cell Counting Kit (CCK-8, Dojindo, Kumamoto, Japan). L02 cells were seeded into a 96-well plate at $0.7 \times 10^{4}$ cells/well. The next day, the medium was replaced with DMEM containing sodium palmitate/BSA at concentrations ranging between 25 and $400 \mu \mathrm{M}$, or $0.4 \%$ low free fatty acid BSA only. After 24 or $48 \mathrm{~h}, 10 \mu \mathrm{l}$ of CCK-8 reagent was added to $100 \mu$ l cultures. Two hours later, absorbance was measured at $450 \mathrm{~nm}$ using a microplate reader (BioTek Synergy2, Winooski, VT, USA).

\section{Real-time PCR}

Total RNA was extracted from cells using TRIzol reagent (Invitrogen), and CDNA was synthesized using a High capacity reverse transcription kit (Applied Biosystems, Foster City, CA, USA), following the manufacturer's protocols. Quantitative real-time PCR was performed using an ABI 7500 detection system (Applied Biosystems) with specific primers as follows: h-TRB3-F 5'-TGG TAC CCA GCT CCT CTA CG-3'; h-TRB3-R 5'-GAC AAA GCG ACA CAG CTT GA-3'; h-ATF4-F 5'- CCT GTC CTC CAC TCC AGA TC-3'; h-ATF4-R 5'-ATT TGG AGA GCC CCT GGT AG-3'; h-CHOP-F 5'-CCA CTC TTG ACC CTG CTT CT-3'; h-CHOP-R 5'-TGG TTC TCC CTT GGT CTT CC-3'; h-GAPDH-F 5'-GAA GGT GAA GGT CGG AGT C-3'; h-GAPDH-R 5'-GAA GAT GGT GAT GGG ATT TC-3'. Reactions were performed in a 96-well plate, with each reaction mixture containing $10 \mu \mathrm{l}$ $2 \times$ SYBR Green Master Mix (ABI), 8 pmol forward and reverse primers, and $10 \mu \mathrm{l}$ of template cDNA. The PCR conditions were as follows: $95^{\circ} \mathrm{C}$ for $10 \mathrm{~min}$, then 40 cycles of $95^{\circ} \mathrm{C}$ for $15 \mathrm{~s}$, and $60^{\circ} \mathrm{C}$ for $1 \mathrm{~min}$. The relative changes in gene expression were analyzed by the $2^{-\Delta \triangle \mathrm{CT}}$ method, and normalized to the expression of the reference gene GAPDH.

\section{Construction of expression plasmids and cell transfection}

The plasmid pEGFN1-TRB3 was constructed and synthesized by the Shanghai GeneChem Co., Ltd (Shanghai, China). The coding region of human TRB3 (NM_021158) cDNA was amplified by PCR (upstream primer: 5'-TCC GCT CGA GAT GCG AGC CAC CCC TCT G-3'; downstream primer: 5'- ATC GGA ATT CCT AGC CAT ACA GAA CCA CTT C-3', amplicon: 1,097 bp) and inserted into the vector pEGFN1 between XhoI and EcoRI sites. The corresponding control vector without TRB3 cDNA used the sequence 5'-TTC TCC GAA CGT GTC ACG T-3' and was constructed in a similar way. Cell transfection was performed in cells that were $60-80 \%$ confluent. The plasmids were transfected using lipofectamine 2000 (Invitrogen), according to the manufacturer's protocol. Transfected cells were then treated with tunicamycin or palmitate after $24 \mathrm{~h}$.

\section{Western blotting}

Protein extraction was performed by lysing the cells in RIPA buffer (Thermo Fisher Scientific) supplemented with a protease inhibitor cocktail (Thermo Fisher Scientific). Thirty to fifty micrograms of the cell lysates were loaded onto a NuPAGE Bis/Tris gel (Novex, Invitrogen), followed by transferring to PVDF membranes using an iBlot ${ }^{\circledR}$ Dry Blotting System (Invitrogen). The membrane was then blocked in $1 \times$ PBS, containing $5 \%$ nonfat dry milk and $0.1 \%$ Tween 20 , for $30 \mathrm{~min}$ at room temperature, followed by incubation with the primary antibodies at room temperature for $3 \mathrm{~h}$. Total and phosphorylated Akt, total and cleaved caspase-3, total and cleaved caspase-7, total and cleaved PARP, CHOP, and GAPDH antibodies (Cell Signaling Technology, Danvers, MA, USA) were diluted 1:1,000 with $1 \times$ PBS, 3\% BSA, and $0.1 \%$ Tween 20 . The ATF4 and TRB3 antibodies were purchased from Santa Cruz Biotechnology (Santa Cruz, CA, USA) and diluted 
1:250. Following incubation with respective primary antibodies, the membranes were then washed three times for 10 min with $1 \times$ PBST and incubated with HRP-conjugated anti-rabbit or anti-mouse secondary antibodies (Cell Signaling Technology) at a final dilution of 1:2,000. After three subsequent washes with 1× PBST, antibody binding was detected using ECL chemiluminescence substrates (Pierce, Rockford, IL, USA), and captured with a ChemiDoc Imaging system (Bio-Rad Laboratories, Hercules, CA, USA). The expression of GAPDH was used as a control.

\section{Mitochondrial membrane potential assay}

Cells were seeded into a 96-well plate at a density of $0.5 \times 10^{4}$ cells/well. The next day, the medium was replaced with DMEM containing $200 \mu \mathrm{M}$ palmitate, $0.4 \%$ low free fatty acid BSA as negative control, or $10 \mu \mathrm{g} / \mathrm{ml}$ tunicamycin as a positive control. After $12-48 \mathrm{~h}$, mitochondrial membrane potentials were detected using a JC-1 Mitochondrial Membrane Potential Assay Kit (Abnova, Taipei, Taiwan), according to the manufacturer's protocol. Labeled cells were observed using an inverted fluorescence microscope (TMS, Nikon, Tokyo, Japan); healthy cells with J-aggregates appeared red, and apoptotic or unhealthy cells with JC1-monomers appeared green. Furthermore, the ratio of green to red fluorescent intensity was measured using a black 96-well plate in a microplate reader (Bio-Tek Instruments). The ratio of fluorescent intensity of JC1-monomers (excitation at $485 \mathrm{~nm}$ and emission at $535 \mathrm{~nm}$ ) to J-aggregates (excitation at $560 \mathrm{~nm}$ and emission at $595 \mathrm{~nm}$ ) was used as an indicator of cell apoptosis.

\section{DAPI (4', 6'-diamidino-2-phenylindole) staining}

To visualize the effect of palmitate on nuclear morphology, L02 cells were stained with DAPI (4', 6'-diamidino-2-phenylindole; Sigma). Briefly, cells were washed twice with PBS, fixed with 4\% paraformaldehyde for $10 \mathrm{~min}$, and stained with $5 \mu \mathrm{g} / \mathrm{ml}$ DAPI diluted in $0.1 \%$ Triton X-100 in PBS solution, for $10 \mathrm{~min}$ at room temperature. Images were acquired with a fluorescence microscope using an excitation wavelength of $340 \mathrm{~nm}$.

\section{Annexin V/PI staining and flow cytometry}

Flow cytometry was used to determine the effect of palmitate on cell viability and apoptosis. For this experiment, cells were seeded in 6-well plates at a density of $0.7 \times 10^{5} \mathrm{cells} / \mathrm{ml}$ and cultured overnight. Cells were then treated with $200 \mu \mathrm{M}$ sodium palmitate, $0.4 \%$ low free fatty acid BSA or $10 \mu \mathrm{g} / \mathrm{ml}$ tunicamycin for 12 and $24 \mathrm{~h}$. The collected cells were then resuspended in Annexin V-FITC/Propidium Iodide staining solution (Dojindo, Kumamoto, Japan), incubated in dark at room temperature for $10 \mathrm{~min}$, and then analyzed by flow cytometry (FACSCalibur, Becton-Dickinson, CA, USA). Cells in the lower left quadrant were not stained with either PI or Annexin V-FITC, and were considered to be live cells. Annexin V-FITC-positive cells in the lower right quadrant were considered to be in the early stages of apoptosis. Cells that were both PI and Annexin V-FITC positive in the upper right quadrant were considered to be in the late stages of apoptosis. Based on these considerations, the percentage of apoptotic cells was calculated as a proportion of $1 \times 10^{4}$ total cells with CellQuest (Macintosh platform) programs.

\section{Co-immunoprecipitation assay}

Co-Immunoprecipitation of TRB3 and Akt was performed using a co-immunoprecipitation kit (Thermo Fisher Scientific) according to the manufacturer's instructions. In brief, TRB3 antibody was coupled to the AminoLink Resin in a Spin Column and stored at $4{ }^{\circ} \mathrm{C}$. L02 cells were seeded into 6-cm dishes at a density of $2 \times 10^{5}$ cells per dish and grown overnight. The next day, cells were collected after treated with BSA or tunicamycin $(10 \mu \mathrm{g} / \mathrm{ml})$ for $6 \mathrm{~h}$, then lysed and incubated with the prepared anti-TRB3-coupled or control resin, overnight at $4^{\circ} \mathrm{C}$. After excess proteins were removed, the target proteins bound to the anti-TRB3coupled resin were eluted and subjected to western blotting to detect Akt expression levels.

\section{Statistical analysis}

All experiments were performed at least three times, and the results were presented as mean \pm standard deviation (SD). Differences between two groups were assessed using a Student's $t$-test with SPSS software v19.0 (IBM Corp., Armonk, NY, USA). A $P$-value $<0.05$ was considered to be statistically significant. 
Fig. 1. Palmitate decreases L02 cell viability. The viability of L02 cells treated with BSA (control) or palmitate at different doses (ranging between 25 and $400 \mu \mathrm{M}$ ) for 24 or $48 \mathrm{~h}$ is presented ( $\mathrm{n}=4$ for each group). It showed that palmitate inhibited L02 cell growth significantly when its concentration was up to $200 \mu \mathrm{M}$. Data are presented as means \pm SD of percentage of the viability of control, which was assigned the value of $100 \%$. ${ }^{*} P<0.05$; $\# P<0.01$ vs. control.

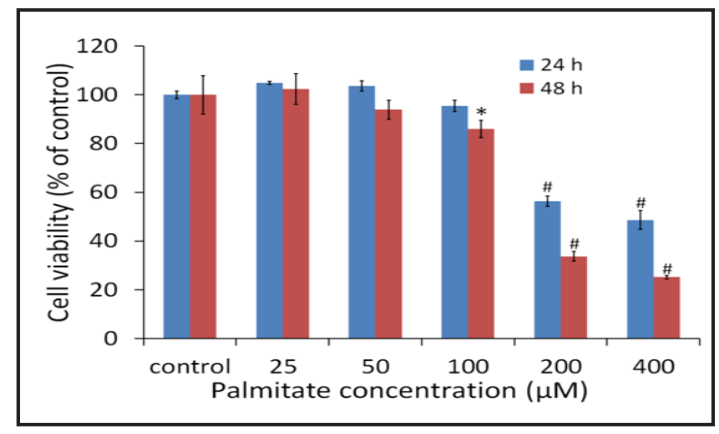

Fig. 2. Palmitate reduces mitochondrial membrane potential. Representative images of L02 cells stained with the dye JC-1 are shown (A). Healthy cells fluoresce red and unhealthy/ apoptotic cells fluoresce green. The following experimental conditions are presented: treatment with $0.4 \%$ low free fatty acid BSA (negative control) for 12 (a), 24 (d) and $48 \mathrm{~h} \mathrm{(g);}$ treatment with $200 \mu \mathrm{M}$ palmitate for 12 (b), 24 (e) and $48 \mathrm{~h}(\mathrm{~h})$; and treatment with $10 \mu \mathrm{g} / \mathrm{ml}$ tunicamycin (positive control) for 12 (c), 24 (f) and $48 \mathrm{~h}$ (i). Changes in cell fluorescence were also measured quantitatively and expressed as the ratio of green to red fluorescence in cells after different treatment as indicated for 24 and $48 \mathrm{~h}$ ( $\mathrm{n}=4$ for each group) (B). Data are presented as means $\pm \mathrm{SD}$; $P<0.01$ vs. BSA.

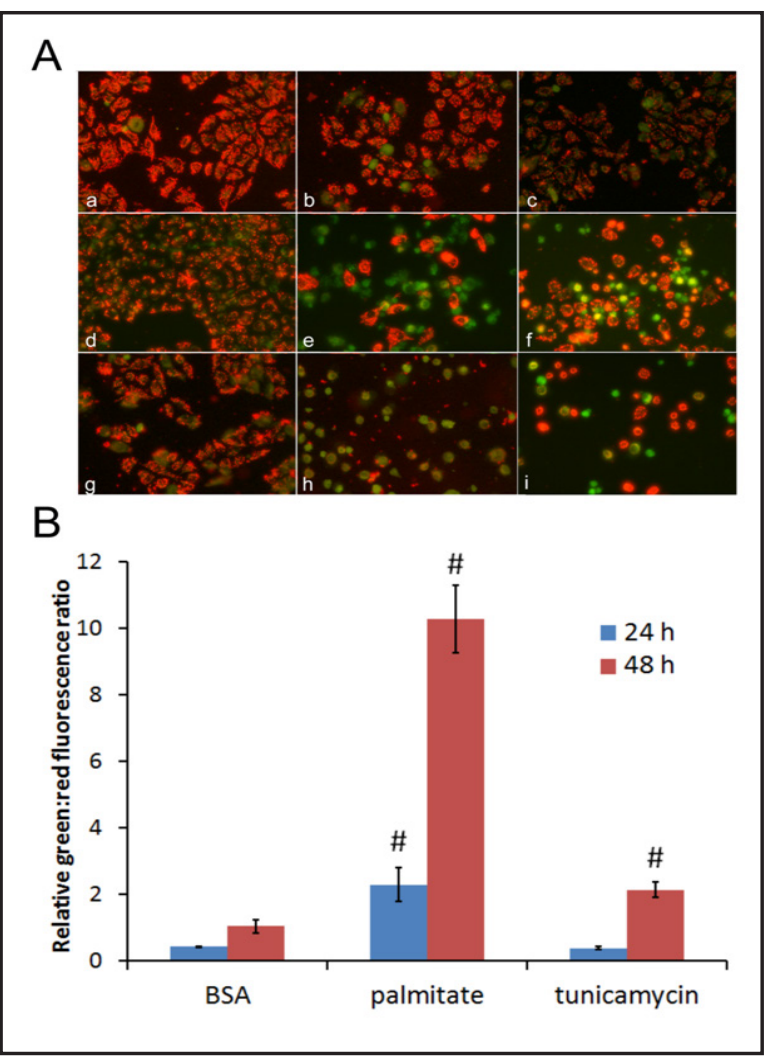

\section{Results}

Palmitate exposure decreases cell viability

The effect of various concentrations of palmitate on L02 cell viability after 24 and $48 \mathrm{~h}$ was determined (Fig. 1). Our results showed that palmitate significantly reduced cell viability in a dose-dependent manner. While palmitate had little effect on L02 cell viability at lower concentrations, significant toxicity was observed at doses of 200 and $400 \mu \mathrm{M}$. Given the toxic effects of $200 \mu \mathrm{M}$, this concentration of palmitate was used for the following experiments.

\section{Palmitate changes mitochondrial membrane potential}

Next, we examined the effect of palmitate on the mitochondrial membrane potential of L02 cells. This was achieved using the fluorescent dye JC-1, which has been widely used to detect mitochondrial depolarization during apoptosis [27]. Microscopy of JC-1-stained cells showed that most control cells had intense red fluorescence and weak green fluorescence, indicating that these cells were healthy (Fig. 2A). Incubation with $200 \mu \mathrm{M}$ palmitate for various time periods was associated with increased green fluorescence, suggesting that palmitate induced apoptosis in L02 cells (Fig. 2A). Quantitative analysis of JC-1 staining yielded a similar result 


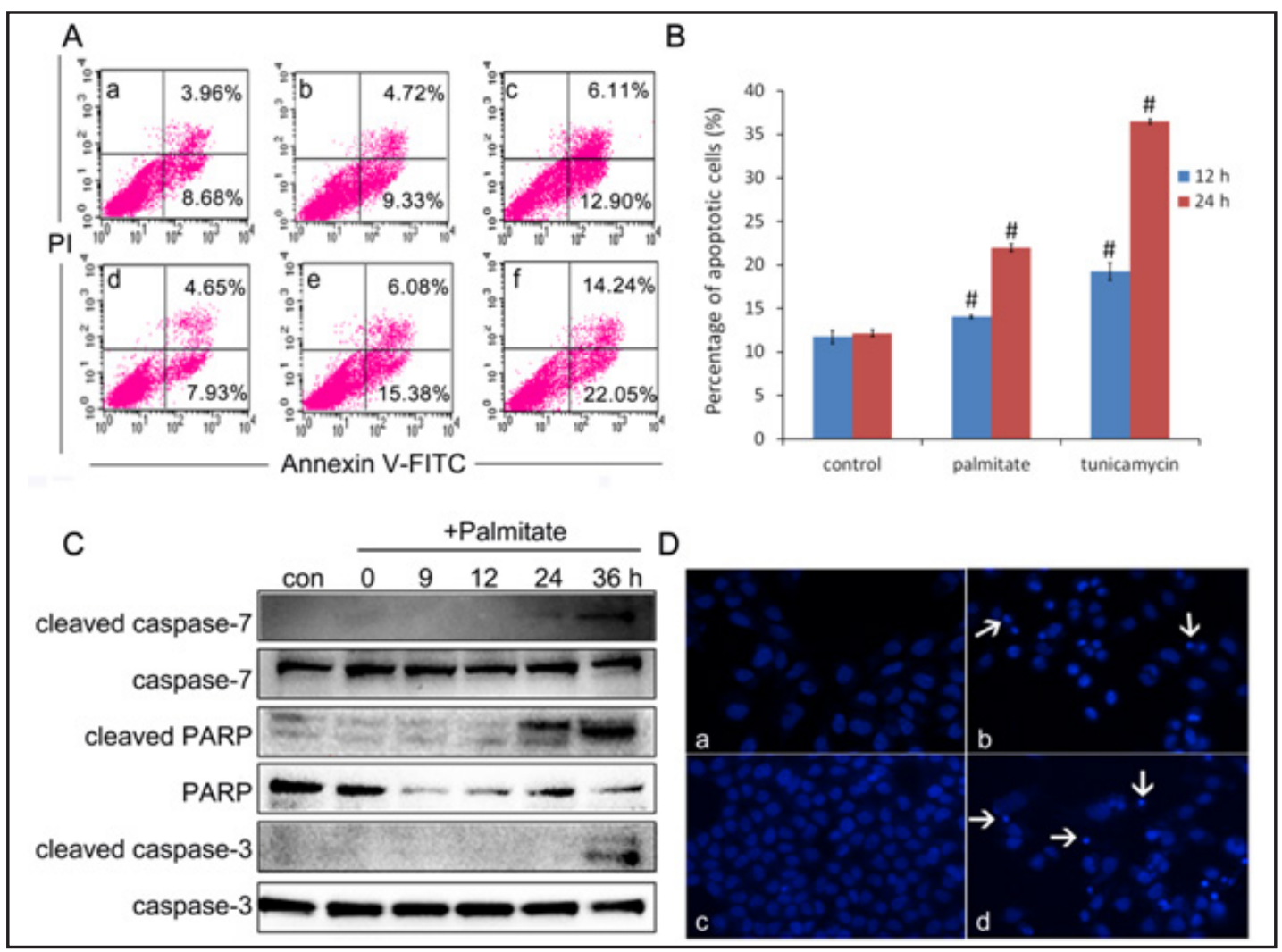

Fig. 3. Palmitate induces apoptosis in L02 cells. Annexin V and propidium iodide staining, as detected by flow cytometry, is shown for cells treated with BSA (negative control), $10 \mu \mathrm{g} / \mathrm{ml}$ tunicamycin and $200 \mu \mathrm{M}$ palmitate (A). The numbers shown in the lower or upper right indicate the percentage of early or late apoptotic cells, respectively. The following experimental conditions are presented: BSA-treated cells for 12 (a) and $24 \mathrm{~h}$ (d); palmitate treated cells for 12 (b) and $24 \mathrm{~h} \mathrm{(e);} \mathrm{and} \mathrm{tunicamycin-treated} \mathrm{cells} \mathrm{for} 12$ (c) and 24 $\mathrm{h}(\mathrm{f})$. The percentage of apoptotic cells for each experimental condition described above is also presented within the histograms (B); All data are presented as the mean $\pm \mathrm{SD}(\mathrm{n}=3$ for each group); $P<0.01$ vs. BSA. The expression levels of cleaved PARP and caspases associated with apoptosis were also determined by Western blotting in cells treated with $200 \mu \mathrm{M}$ palmitate for $0-36 \mathrm{~h}$ as indicated (C). Nuclear morphology of treated cells was determined using DAPI staining and fluorescence microscopy (D). Representative images of the following experimental conditions are shown: BSA-treated cells at $12 \mathrm{~h} \mathrm{(a)}$; palmitate treated cells at $12 \mathrm{~h}$ (b); BSA-treated cells at $24 \mathrm{~h}$ (c); and palmitate treated cells at $24 \mathrm{~h}$ (d). Evidence of apoptotic cells are indicated by arrows. Magnification $=200 \times$.

(Fig. 2B). Thus, palmitate induced depolarization of the mitochondrial membrane potential and increased apoptosis in L02 cells.

\section{Palmitate induces apoptosis in L02 cells}

Our mitochondrial membrane potential data indicated that palmitate induced L02 cell apoptosis, which was confirmed in follow-up experiments. Specifically, we observed that palmitate treatment increased the percentage of apoptotic cells as determined by flow cytometry after annexin V-FITC and PI staining (Fig. 3A; B). Next, Western blot analysis was used to detect the cleavage of PARP and caspases, which serves as markers of cells undergoing apoptosis as well. The expression levels of cleaved PARP, cleaved caspase- 3 and -7 were increased following palmitate exposure, while a reduction of PARP and no significant changes of caspase-3 and -7 were observed (Fig. 3C). Lastly, nuclear morphological changes observed by fluorescense microscopy after DAPI nuclear staining were also indicative of palmitate-induced apoptosis (Fig. 3D). These data were consistent with the effect of palmitate 
A
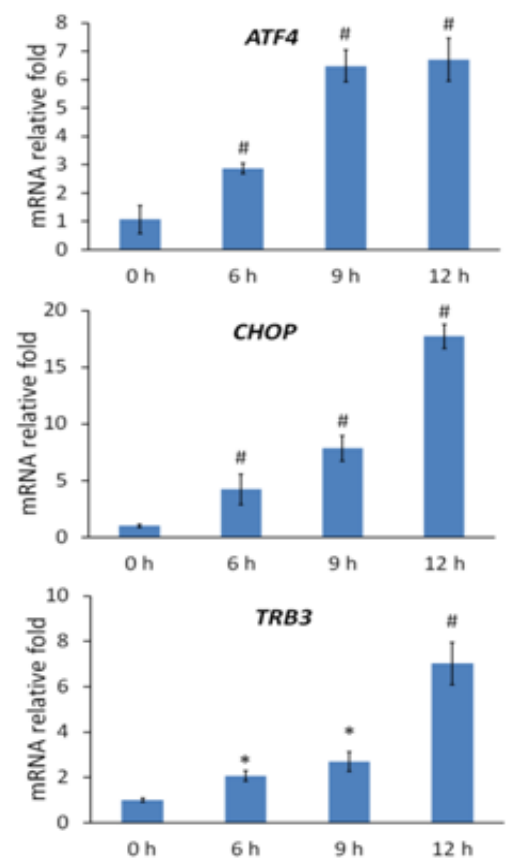

B
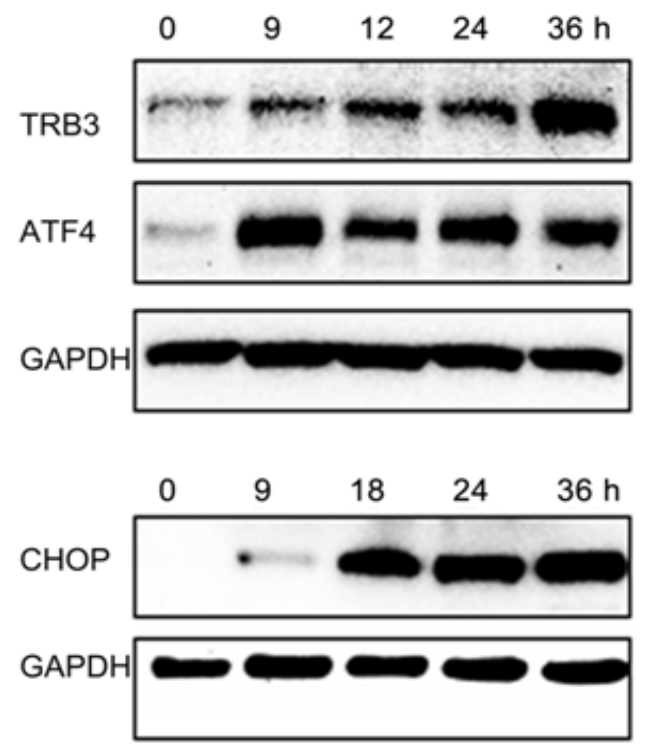

Fig. 4. Palmitate increases TRB3, ATF4 and CHOP expression. The levels of TRB3, ATF4 and CHOP mRNA were analyzed by real-time PCR after L02 cells treated with $200 \mu \mathrm{M}$ palmitate for different hours $(0-12 \mathrm{~h})$ as indicated. It showed that all were significantly increased in a time-dependent manner (A); All data are presented as the mean \pm SD $(\mathrm{n}=3$ for each group); * $P<0.05$; \# $P<0.01 \mathrm{vs.} 0 \mathrm{~h}$. The protein levels of TRB3, ATF4 and CHOP were also estimated by Western blotting after L02 cells treated with $200 \mu \mathrm{M}$ palmitate for the indicated hours ( 0 - $36 \mathrm{~h})$. Upregulation of TRB3, ATF4 and CHOP was observed (B).

on mitochondrial membrane potential, and further suggested that palmitate exposure was associated with caspase activation and apoptosis in L02 cells.

Palmitate induces TRB3 expression and ER stress

To elucidate the possible mechanism through which palmitate induces apoptosis, we analyzed the expression level of TRB3 and ER stress after L02 cells treated with $200 \mu \mathrm{M}$ palmitate for different hours $(0-36 \mathrm{~h})$. For this analysis, we focused on the ATF4-CHOP pathway, as it has previously been shown that ATF6 and IRE1 are not major pathways for palmitate-induced ER stress in L02 cells [15]. In this regard, our real-time PCR and Western blot analyses showed that the mRNA and protein expression levels of ATF4, TRB3, and CHOP were all significantly increased by palmitate exposure in a time-dependent manner. (Fig. 4).

TRB3 overexpression decreases L02 cell viability and induces apoptosis

We next evaluated the effect of TRB3 overexpression on palmitate-induced cell apoptosis in L02 cells. Transfection of L02 cells with the TRB3 plasmid significantly elevated TRB3 expression at both the protein and mRNA level, compared to the negative control (Fig. $5 A)$. The viability of L02 cells overexpressing TRB3 was reduced, and these cells responded worse when exposed to palmitate and tunicamycin (Fig. 5B). The nuclear morphology of L02 cells overexpressing TRB3 was indicative of apoptosis, which was also evident in palmitateand tunicamycin-treated cells (Fig. 5C). Consistent with these data, L02 cells overexpressing TRB3 treated with palmitate or tunicamycin had elevated expression levels of cleaved caspase-3 (Fig. 5D). Mechanistically, the deleterious effects of excess TRB3 expression was not associated with upregulation of the ATF4-CHOP pathway, as evidenced by unchanged protein expression levels of ATF4 and CHOP in L02 cells overexpressing TRB3 (Fig. 6). 


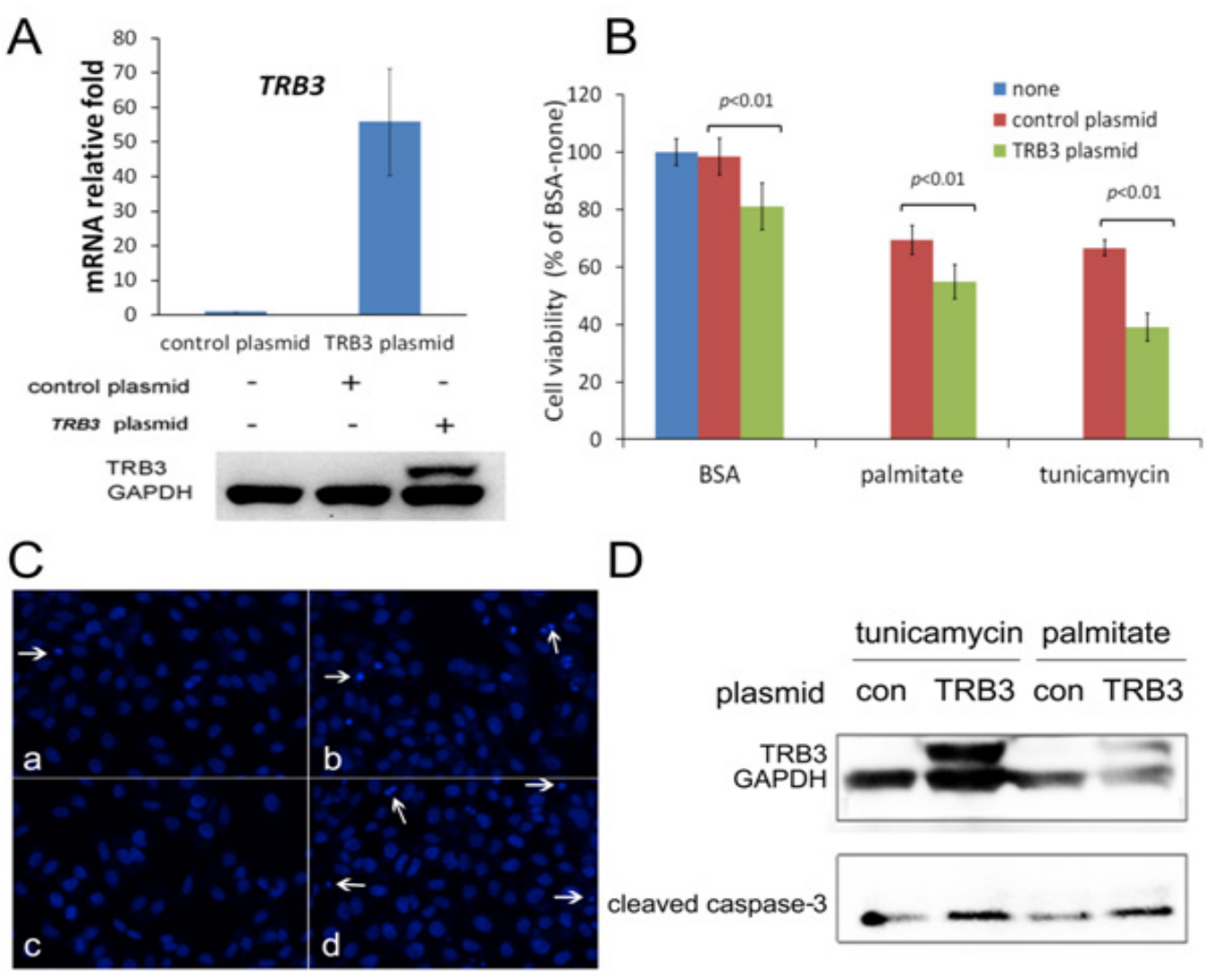

Fig. 5. TRB3 overexpression reduces L02 cell viability and induces apoptosis. L02 cells transfected with a TRB3 expression vector had significantly increased levels of TRB3 at the mRNA and protein level (A). Overexpression of TRB3 decreased cell viability, and exacerbated detrimental effects of $10 \mu \mathrm{g} / \mathrm{ml}$ tunicamycin or $200 \mu \mathrm{M}$ palmitate after $24 \mathrm{~h}$ (B). Representative images of DAPI-stained cells indicate that TRB3 overexpression induced apoptosis (C). The following experimental conditions are presented: control plasmid $+200 \mu \mathrm{M}$ palmitate (a); TRB3 plasmid + $200 \mu \mathrm{M}$ palmitate (b), control plasmid + BSA (c); and TRB3 plasmid + BSA (d). Evidence of apoptotic cells are indicated by arrows. Magnification $=200 \times$. Finally, the protein expression level of cleaved caspase-3 was determined, indicating TRB3 overexpression induces apoptosis (D).

Fig. 6. TRB3 overexpression has no effect on the expression of ATF4 and CHOP. Representative western blots are shown for lysates of TRB3-overexpressing L02 cells treated with BSA (lane 3) and treated with $200 \mu \mathrm{M}$ palmitate (lane 4) for $12 \mathrm{~h}$. Data from untransfected cells treated with BSA (lane 1), and 200 $\mu \mathrm{M}$ palmitate (lane 2) for $12 \mathrm{~h}$ are also shown. It found that protein levels of ATF4 and CHOP were not changed significantly in the presence of TRB3 overexpression.

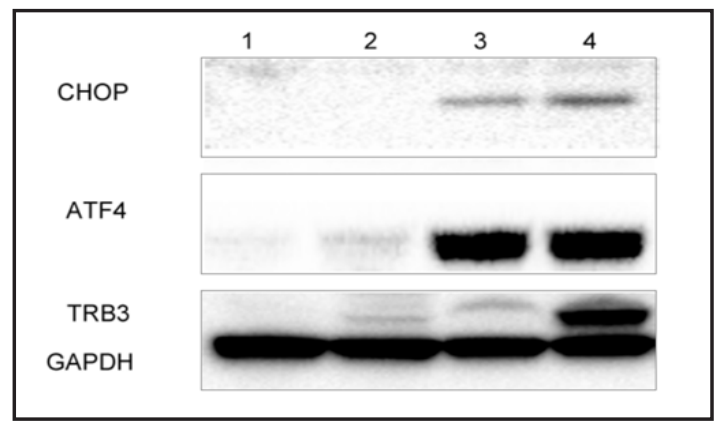

\section{TRB3 interacts with Akt}

Finally, we wanted to investigate whether TRB3 had an effect on the phosphorylation of Akt during palmitate-induced ER stress in L02 cells. Our data indicated that the level of Akt (S473) phosphorylation was reduced by palmitate in a time-dependent manner (Fig. 7A), in accordance with the upregulation of TRB3 (Fig. 4B). Furthermore, TRB3 overexpression 
Fig. 7. TRB3 overexpression inhibits the phosphorylation of Akt. A representative Western blot shows the expression level of phosphorylated Akt (S473) in L02 cells was inhibited after treated with $200 \mu \mathrm{M}$ palmitate for different hours as indicated (A). Similarly, the effect of TRB3 overexpression also reduced the phosphorylation state of Akt in cells treated with $200 \mu \mathrm{M}$ palmitate or $10 \mu \mathrm{g} / \mathrm{ml}$ tunicamycin (B). Coimmunoprecipitation of TRB3 with Akt indicates that these two proteins interact with each other $(\mathrm{C})$. The following experimental conditions are presented: cells treated with

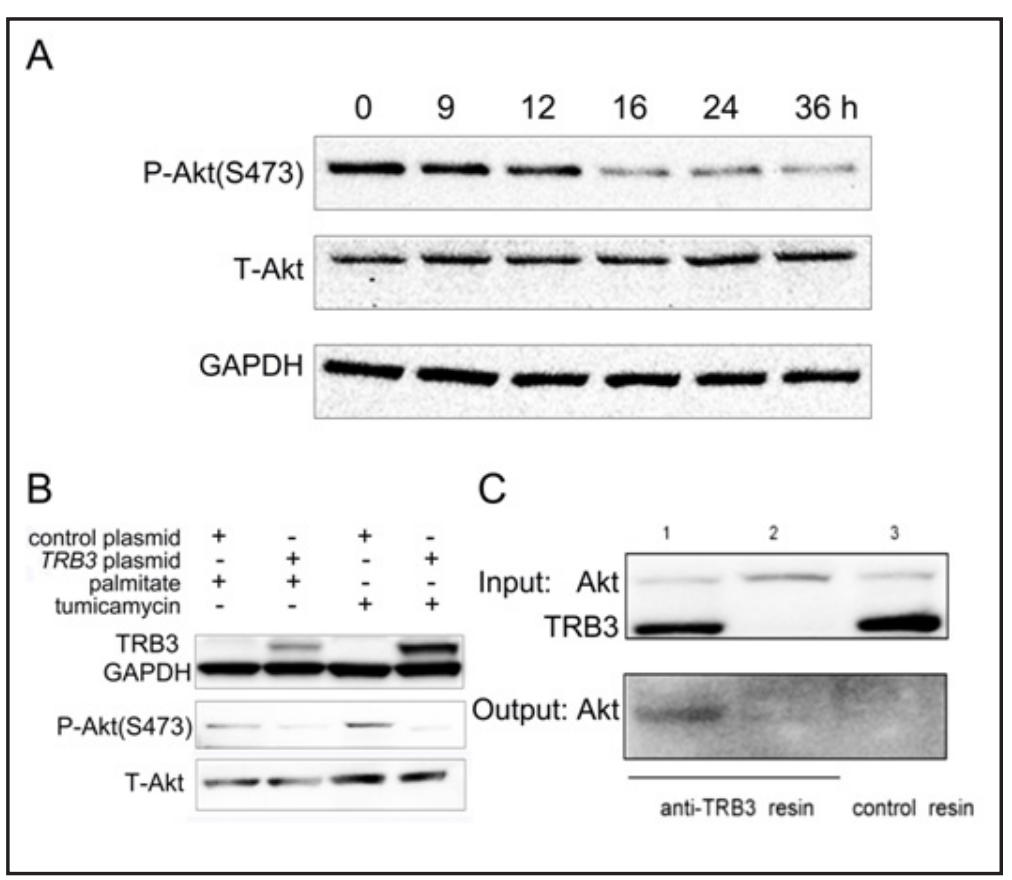
$10 \mu \mathrm{g} / \mathrm{ml}$ tunicamycin for $6 \mathrm{~h}$ and then lysates incubated with anti-TRB3 resin (lane 1), BAS-treated cell lysates incubated with anti-TRB3 resin (lane 2) and cells treated with $10 \mu \mathrm{g} / \mathrm{ml}$ tunicamycin and then lysates incubated with the control resin (lane 3).

further exacerbated the inhibition of Akt (S473) phosphorylation induced by palmitate or tunicamycin (Fig. 7B). Co-immunoprecipitation studies revealed that endogenous TRB3 interacts with Akt and inhibits the phosphorylation of Akt (Fig. 7C).

\section{Discussion}

TRB3 is a mammalian homolog of Drosophila tribbles, which can be induced under conditions of ER stress, such as fasting [24], hypoxia [28], ethanol exposure [29], and glucose or amino acid deprivation [19]. It has also been demonstrated that ER stress contributes to the induction of apoptosis in human liver cells exposed to saturated fatty acids [15]. Thus, we hypothesized that saturated fatty acids augment TRB3 expression under conditions of ER stress and lead to apoptosis in human liver cells. It has previously been shown that the effect of TRB3 on survival or apoptosis are dependent on the cell type and context $[18,23$, 30-34]. Here, we have demonstrated for the first time that TRB3 is significantly increased at the protein and mRNA level during palmitate-induced ER stress in the normal human liver cell line, L02, and that this higher expression level is associated with increased apoptosis. Moreover, overexpression of TRB3 in L02 cells aggravated the deleterious effects of palmitate, indicating that TRB3 expression is correlated with ER stress and apoptosis induced by saturated fatty acids in liver cells.

The ER stress response is an important compensatory mechanism that attempts to overcome the accumulation of misfolded proteins in the ER. Despite this cytoprotective effect, prolonged or severe ER stress can lead to pro-apoptotic signals that impede normal cellular functions $[12,35]$. The UPR is an adaptive response mechanism that can reestablish normal homeostasis in the ER. This signaling mechanism is mediated by three integrated pathways that are activated through the ER transmembrane sensors PERK, IRE1 $\alpha$ and ATF6 [35]. Among these three sensors, PERK has been described as an important factor for activation 
of caspases, ultimately leading to apoptotic cell death by activating ATF4 and CHOP[35]. In this study, we confirmed that palmitate exposure induced the ATF4-CHOP pathway, and promoted apoptosis in L02 cells.

Interestingly, the ATF4-CHOP pathway has been previously shown to induce TRB3 expression under conditions of ER stress, and that TRB3 can reciprocally repress the function of ATF4 and CHOP [22, 36]. Specifically, Ohoka et al. [22] showed that CHOP and ATF4 cooperate to activate the TRB3 promoter. In turn, TRB3 interacts with a TRB3-binding region in the transactivation domain of CHOP, indicating that this interaction may suppress the transactivation activity of CHOP. However, CHOP expression levels were unchanged by coexpression with TRB3 or knockdown of endogenous TRB3 [22]. Consistent with these data, the results obtained in this study shows that ATF4-CHOP levels were not significantly altered by overexpression of TRB3. Thus, TRB3 can inhibit the activity of CHOP and ATF4, but it does not promote their degradation. Since CHOP is also induced by palmitate, it is possible that the CHOP-TRB3 pathway operates in response to palmitate as well; however, the negative effects of TRB3 on the ATF4-CHOP pathway does not account for the promotion of palmitate-induced apoptosis in L02 cells. Based on these findings, we presume that TRB3 causes apoptosis by a mechanism separate from blocking the transactivation of CHOP.

Akt (also called protein kinase B or PKB), is a serine-threonine kinase known to sustain cell survival by inhibiting apoptosis [37]. There have been several reports that TRB3 binds Akt and negatively regulates Akt activation [24, 30, 33, 38]. Therefore, we speculated that TRB3 contributes to palmitate-induced apoptosis by regulating the Akt pathway. Our current data shows that Akt phosphorylation at S473 was reduced by palmitate in a time-dependent manner. Furthermore, overexpression of TRB3 further reduced the phosphorylation of Akt in L02 cells under conditions of palmitate or tunicamycin-induced ER stress. These results suggest that TRB3 inhibits Akt activation in L02 cells during ER stress. Interestingly, our co-immunoprecipitation data confirms that TRB3 interacts with Akt in L02 cells, as has previously been reported in hepatoma HepG2 cells [24]. We interpret these data to indicate that although TRB3 can partially suppress ATF4 and CHOP function, it is not sufficient to protect cells against the inhibition of Akt phosphorylation induced by palmitate.

In conclusion, TRB3 plays an important role in modulating palmitate-induced ER stress and apoptosis in L02 cells. While there is compelling evidence to indicate that hepatocyte lipotoxicity and apoptosis is the cause of PNALD $[9,10]$, a definitive mechanism remains unclear. We speculate that ER stress-dependent apoptosis may be involved in the pathogenesis of PNALD, and that the effect of TRB3 on the ATF4/CHOP and Akt pathway may be part of the molecular mechanism underlying PNALD. We are currently undertaking in vivo studies to test these hypotheses, and to establish that TRB3 is an important contributor to the pathogenesis of PNALD.

\section{Acknowledgements}

This study was supported by grants from Shanghai Key Laboratory of Pediatric Gastroenterology and Nutrition (11DZ2260500) and the National Natural Science Foundation of China (81100631). We sincerely thank the staff of Shanghai Key Laboratory of Pediatric Gastroenterology and Nutrition for their advice and help.

\section{References}

1 Cober MP, Teitelbaum DH: Prevention of parenteral nutrition-associated liver disease: Lipid minimization. Curr Opin Organ Transplant 2010;15:330-333.

2 Tillman EM: Review and clinical update on parenteral nutrition-associated liver disease. Nutr Clin Pract 2013;28:30-39. 
3 Xu ZW, Li YS: Pathogenesis and treatment of parenteral nutrition-associated liver disease. Hepatobiliary Pancreat Dis Int 2012;11:586-593.

- 4 Forchielli ML, Walker WA: Nutritional factors contributing to the development of cholestasis during total parenteral nutrition. Adv Pediatr 2003;50:245-267.

-5 Gabe SM: Lipids and liver dysfunction in patients receiving parenteral nutrition. Curr Opin Clin Nutr Metab Care 2013;16:150-155.

-6 Leamy AK, Egnatchik RA, Young JD: Molecular mechanisms and the role of saturated fatty acids in the progression of non-alcoholic fatty liver disease. Prog Lipid Res 2013;52:165-174. Trauner M, Arrese M, Wagner M: Fatty liver and lipotoxicity. Biochim Biophys Acta 2010;1801:299-310. Wang D, Wei Y, Pagliassotti MJ: Saturated fatty acids promote endoplasmic reticulum stress and liver injury in rats with hepatic steatosis. Endocrinology 2006;147:943-951.

-9 Cai W, Wu J, Hong L, Xu Y, Tang Q Shi C: Oxidative injury and hepatocyte apoptosis in total parenteral nutrition-associated liver dysfunction. J Pediatr Surg 2006;41:1663-1668.

10 Hong L, Wang X, Wu J, Cai W: Mitochondria-initiated apoptosis triggered by oxidative injury play a role in total parenteral nutrition-associated liver dysfunction in infant rabbit model. J Pediatr Surg 2009;44:17121718.

11 Pineau L, Colas J, Dupont S, Beney L, Fleurat-Lessard P, Berjeaud JM, Berges T, Ferreira T: Lipid-induced er stress: Synergistic effects of sterols and saturated fatty acids. Traffic 2009;10:673-690.

12 Basseri S, Austin RC: Er stress and lipogenesis: A slippery slope toward hepatic steatosis. Dev Cell 2008;15:795-796.

13 Kim DS, Jeong SK, Kim HR, Kim DS, Chae SW, Chae HJ: Metformin regulates palmitate-induced apoptosis and er stress response in hepg2 liver cells. Immunopharmacol Immunotoxicol 2010;32:251-257.

14 Wei Y, Wang D, Pagliassotti MJ: Saturated fatty acid-mediated endoplasmic reticulum stress and apoptosis are augmented by trans-10, cis-12-conjugated linoleic acid in liver cells. Mol Cell Biochem 2007;303:105113.

15 Cao J, Dai DL, Yao L, Yu HH, Ning B, Zhang Q Chen J, Cheng WH, Shen W, Yang ZX: Saturated fatty acid induction of endoplasmic reticulum stress and apoptosis in human liver cells via the perk/atf4/chop signaling pathway. Mol Cell Biochem 2012;364:115-129.

16 Reimund JM, Rahmi G, Escalin G, Pinna G, Finck G, Muller CD, Duclos B, Baumann R: Efficacy and safety of an olive oil-based intravenous fat emulsion in adult patients on home parenteral nutrition. Aliment Pharmacol Ther 2005;21:445-454.

17 Hegedus Z, Czibula A, Kiss-Toth E: Tribbles: Novel regulators of cell function; evolutionary aspects. Cell Mol Life Sci 2006;63:1632-1641.

18 Ord D, Meerits K, Ord T: Trb3 protects cells against the growth inhibitory and cytotoxic effect of atf4. Exp Cell Res 2007;313:3556-3567.

19 Schwarzer R, Dames S, Tondera D, Klippel A, Kaufmann J: Trb3 is a pi 3-kinase dependent indicator for nutrient starvation. Cell Signal 2006;18:899-909.

20 Kiss-Toth E: Tribbles: 'Puzzling' regulators of cell signalling. Biochem Soc Trans 2011;39:684-687.

-21 Avery J, Etzion S, DeBosch BJ, Jin X, Lupu TS, Beitinjaneh B, Grand J, Kovacs A, Sambandam N, Muslin AJ: Trb3 function in cardiac endoplasmic reticulum stress. Circ Res 2010;106:1516-1523.

22 Ohoka N, Yoshii S, Hattori T, Onozaki K, Hayashi H: Trb3, a novel er stress-inducible gene, is induced via atf4-chop pathway and is involved in cell death. EMBO J 2005;24:1243-1255.

23 Morse E, Schroth J, You YH, Pizzo DP, Okada S, Ramachandrarao S, Vallon V, Sharma K, Cunard R: Trb3 is stimulated in diabetic kidneys, regulated by the er stress marker chop, and is a suppressor of podocyte mcp-1. Am J Physiol Renal Physiol 2010;299:F965-972.

24 Du K, Herzig S, Kulkarni RN, Montminy M: Trb3: A tribbles homolog that inhibits akt/pkb activation by insulin in liver. Science 2003;300:1574-1577.

25 Lima AF, Ropelle ER, Pauli JR, Cintra DE, Frederico MJ, Pinho RA, Velloso LA, De Souza CT: Acute exercise reduces insulin resistance-induced trb3 expression and amelioration of the hepatic production of glucose in the liver of diabetic mice. J Cell Physiol 2009;221:92-97.

26 Wang YG, Shi M, Wang T, Shi T, Wei J, Wang N, Chen XM: Signal transduction mechanism of trb3 in rats with non-alcoholic fatty liver disease. World J Gastroenterol 2009;15:2329-2335. 
27 Shieh JM, Huang TF, Hung CF, Chou KH, Tsai YJ, Wu WB: Activation of c-jun n-terminal kinase is essential for mitochondrial membrane potential change and apoptosis induced by doxycycline in melanoma cells. Br J Pharmacol 2010;160:1171-1184.

28 Bowers AJ, Scully S, Boylan JF: Skip3, a novel drosophila tribbles ortholog, is overexpressed in human tumors and is regulated by hypoxia. Oncogene 2003;22:2823-2835.

29 He L, Simmen FA, Mehendale HM, Ronis MJ, Badger TM: Chronic ethanol intake impairs insulin signaling in rats by disrupting akt association with the cell membrane. Role of trb3 in inhibition of akt/protein kinase b activation. J Biol Chem 2006;281:11126-11134.

30 Zhang J, Wen HJ, Guo ZM, Zeng MS, Li MZ, Jiang YE, He XG, Sun CZ: Trb3 overexpression due to endoplasmic reticulum stress inhibits akt kinase activation of tongue squamous cell carcinoma. Oral Oncol 2011;47:934939.

-31 Kurvinen A, Nissinen MJ, Gylling H, Miettinen TA, Lampela H, Koivusalo AI, Rintala RJ, Pakarinen MP: Effects of long-term parenteral nutrition on serum lipids, plant sterols, cholesterol metabolism, and liver histology in pediatric intestinal failure. J Pediatr Gastroenterol Nutr 2011;53:440-446.

-32 Shang YY, Wang ZH, Zhang LP, Zhong M, Zhang Y, Deng JT, Zhang W: Trb3, upregulated by ox-ldl, mediates human monocyte-derived macrophage apoptosis. FEBS J 2009;276:2752-2761.

33 Ding J, Kato S, Du K: Pi3k activates negative and positive signals to regulate trb3 expression in hepatic cells. Exp Cell Res 2008;314:1566-1574.

-34 Jang YY, Kim NK, Kim MK, Lee HY, Kim SJ, Kim HS, Seo HY, Lee IK, Park KG: The effect of tribbles-related protein 3 on er stress-suppressed insulin gene expression in ins-1 cells. Korean Diabetes J 2010;34:312319.

-35 Rasheva VI, Domingos PM: Cellular responses to endoplasmic reticulum stress and apoptosis. Apoptosis 2009;14:996-1007.

-36 Ord D, Ord T: Mouse nipk interacts with atf4 and affects its transcriptional activity. Exp Cell Res 2003;286:308-320.

-37 Rane MJ, Klein JB: Regulation of neutrophil apoptosis by modulation of pkb/akt activation. Front Biosci (Landmark Ed) 2009;14:2400-2412.

-38 Bromati CR, Lellis-Santos C, Yamanaka TS, Nogueira TC, Leonelli M, Caperuto LC, Gorjao R, Leite AR, Anhe GF, Bordin S: Upr induces transient burst of apoptosis in islets of early lactating rats through reduced akt phosphorylation via atf4/chop stimulation of trb3 expression. Am J Physiol Regul Integr Comp Physiol 2011;300:R92-100. 